\title{
SUSTENTABILIDADE E INOVAÇÃO NA ADMINISTRAÇÃO DA INFORMAÇÃO
}

\section{ARTIGO ORIGINAL}

SILVA, Dione Gelton da ${ }^{1}$

SILVA, Dione Gelton da. Sustentabilidade e Inovação na Administração da Informação. Revista Científica Multidisciplinar Núcleo do Conhecimento. Ano 06, Ed. 01, Vol. 02, pp. 05-13. Janeiro de 2021. ISSN: 2448-0959, Link de acesso: https://www.nucleodoconhecimento.com.br/tecnologia/administracao-dainformacao

\section{RESUMO}

Contemporaneamente, grandes organizações têm demonstrado sua preocupação com sua inovação seja de processos, seja de projetos utilizando a sustentabilidade no seu planejamento, execução e monitoramento. É evidente que há início de escassez de alguns recursos e observa-se também que utilizar o tema sustentável agrega valores diante do mercado, servindo como um diferencial competitivo, num mercado cada vez mais cruel e impessoal. Esta pesquisa objetivou tratar na geração e administração da informação de modo inovador e sustentável em uma organização. Empregou-se a pesquisa do tipo documental e inferiu-se como resultado que a sustentabilidade aliada à inovação tecnológica traz benefícios para os clientes. Portanto, propõe-se que a Tecnologia da Informação (TI) contribua tanto com a inovação, quanto com a sustentabilidade das organizações contemporâneas, consequentemente, gerando valor para elas.

1 Pós-graduado em Gerenciamento de Projetos, Segurança em Redes de Computadores e Gestão da Qualidade de Software; graduado em Bacharel em Ciências da Computação. 
Palavras-chave: Sustentabilidade, inovação, administração da informação, contemporâneo.

\section{INTRODUÇÃO}

Os temas relacionados à sustentabilidade e inovação na geração e administração de informações estão cada vez mais relacionados à agregação de valores, como a obtenção de vantagem competitiva no mercado, ou seja, gerar valor ao negócio e consequentemente para os clientes. O alinhamento da inovação com a sustentabilidade na administração da informação tem demonstrado ser importantes meios a fim de gerar uma melhor estratégia no ambiente de negócios contemporâneos. Deve-se buscar o amplo apoio da alta administração, tais como os executivos e os gestores da organização a fim de que haja uma metodologia de transformação organizacional bem estruturada e que permita a propagação de novas ideias inovadoras e sustentáveis para os membros da organização.

Conforme Dalé; Roldan e Hansen (2011), às Influências ambientais e sociais impostas às instituições atravessam por um conjunto de etapas produtivas, uma vez que a maioria das organizações necessitam estar comprometidas no desenvolvimento de projetos os quais almejam uma etapa de cadeia produtiva de modo sustentável e obviamente, com o objetivo de atender as demandas de mercado.

Para responder às exigências legais, das partes interessadas e da sociedade contemporânea, a maioria das instituições não só têm buscado anexar à sustentabilidade em seus planos e projetos, como também deixar evidente por meio de documentações a respeito dessas questões inerentes à sustentabilidade e à inovação. À vista disso, a administração da informação por meio de ferramentas inovadoras de tecnologia da informação poderá contribuir para uma melhor gestão da informação nas organizações e consequentemente gerando valor. Paulatinamente, grandes empresas, como Google, Amazon e Microsoft têm desenvolvido ferramentas a fim de gerir grande massa de dados utilizando a tecnologia de Big Data e propiciando meios inovadores levando em consideração a sustentabilidade. 
A inovação também é um meio buscado, frequentemente, a fim de gerar valor às organizações e seus clientes.

Embora ainda não tenha muitos estudos os quais abrangem as temáticas da geração e administração das informações de modo sustentável e inovador, este instrumento de pesquisa visa buscar entender como a sustentabilidade e a inovação na administração da informação é tão fundamental para as organizações contemporâneas. Este artigo apresenta dados a respeito da informação, inovação contemporânea ligada à sustentabilidade, a seguir apresenta o gerenciamento de projetos sustentáveis, seguido da sustentabilidade nas organizações contemporâneas e das considerações finais.

\section{INFORMAÇÃO E INOVAÇÃO CONTEMPORÂNEA}

Hodiernamente, a informação é um dos ativos mais relevantes para as organizações e clientes, pois por meio dela pode-se inferir as diversas demandas e soluções. O guia de melhores práticas da Information Technology Infrastructure Library (ITIL) visa alinhar negócios com a tecnologia da informação (TI), ele é excelente para gerenciar diversas informações.

Conforme Bom (2012), o ITIL é composto por cinco exemplares que estão relacionados, ele visa gerar valor por meio do equilíbrio entre utilidade e garantia. A utilidade é o que o cliente recebe, já a garantia é como o serviço é fornecido. O ITIL em sua terceira versão é composto pelos livros de Estratégia de Serviços (foco na estratégia), Desenho de Serviço (planejamento de soluções), Transição de Serviço (desenvolvimento da solução), Operação de Serviço (operações do dia a dia) e Melhoria Contínua (foco no ciclo plan; do; check; act). Eles são fases do ciclo de vida e são compostos por diversos processos, esses têm objetivo de alinhar as demandas de negócio com as ferramentas, processos e procedimentos de informática.

Além do framework de gestão de serviço ITIL, há no mercado outros guias de boas práticas para o gerenciamento da informação, como a ISO 20.000, o Control Objectives for Information and Related Technology (COBIT), CMMI, entre outros. O

Disponível em: https://www.nucleodoconhecimento.com.br/tecnologia/administracao-da- 
COBIT foi desenvolvido pela Information Systems Audit and Control Association (ISACA) para realizar tanto o gerenciamento da governança, quanto da gestão de processos de $\mathrm{Tl}$ a fim de gerar valor para as organizações e seus processos. Sua execução se dá por meio de aplicação de inúmeras práticas de controle que perpetuam desde seu planejamento até seu monitoramento. Portanto, esse guia fornece um conjunto de melhores práticas tanto para governança, quanto gestão de $\mathrm{TI}$ e visa sempre estar alinhada com os objetivos estratégicos da organização. Ele é composto por cinco princípios, são eles: atender às necessidades das partes interessadas, cobrir a organização de ponta a ponta, aplicar um modelo único integrado, permitir uma abordagem holística e distinguir governança de gestão de TI. Tais princípios servem para aumentar a eficiência e eficácia da Tl, aprimorar a segurança da informação, aprimorar os investimentos feitos com a TI e criar uma linguagem comum. Assim, é de grande valia para as organizações.

O primeiro princípio diz respeito ao fornecimento de processos e habilitadores a fim de suportar a criação de valor à organização por meio da TI. No segundo princípio, o COBIT visa cobrir todos os processos e funções da organização de modo que toda a organização esteja coberta de ponta a ponta, ele não só foca nas funções de TI, mas também no tratamento das informações. O terceiro princípio visa unir outros padrões disponíveis no mercado, como ITIL, PMBOK, CMMI, entre outros. Já o quarto princípio trata da implementação da governança de $\mathrm{TI}$, levando-se em consideração vários componentes. E para concluir, o quinto princípio diz respeito a diferenciação entre governança de gestão, os processos de governança são considerados estratégicos, já o de gestão tático é operacional.

Segundo ISACA, além do COBIT há também a ISO 38.500 que trata também de governança de $\mathrm{TI}$, entretanto ele não é tão abrangente quanto o COBIT, pois ele cobre somente a governança de $\mathrm{TI}$, deixando de lado a gestão. O COBIT é composto por conjunto de melhores práticas a fim de garantir a governança e gestão de $\mathrm{TI}$ e consequentemente, melhorar os processos organizacionais. Utilizando-se de modo apropriado, ele fornece não só mais segurança, mas também maior apoio à tomada de decisões.

Disponível em: https://www.nucleodoconhecimento.com.br/tecnologia/administracao-da- 
O principal objetivo da Tl é a criação de valor para as organizações, bem como o gerenciamento dos riscos. Os gestores e executivos visam garantir que os processos de TI cumpram as metas de negócio otimizando os recursos e riscos a fim de atender as necessidades dos clientes. Tanto a governança, quanto o gerenciamento de TI são parte integral da governança corporativa, ou seja, estão intrinsecamente ligadas. A governança de $\mathrm{TI}$ é de responsabilidade dos executivos e gestores (alta administração), porém não são os únicos, pois todos os integrantes da organização devem também utilizar de processos e ferramentas a fim de implantar a governança de modo seguro e sustentável.

\section{GERENCIAMENTO DE PROJETOS INOVADORES E SUSTENTÁVEIS}

As definições de gerenciamento de projetos apresentadas pela literatura e por especialistas são a aplicação de técnicas, ferramentas, habilidades e conhecimentos ao projeto a fim de atender as demandas de negócio. Contemporaneamente, há no mercado inúmeros modelos a fim de efetuar o gerenciamento de projetos, como PMBOK, RUP, Metodologias Ágeis, entre outras. Hoje, o mais utilizado é o PMBOK, ele contempla dez áreas de conhecimento (Tempo, Custo, Integração, Escopo, Risco, Qualidade, Recursos Humanos, Comunicação, Aquisição e Partes Interessadas), cinco grupos de processos (Iniciação, Planejamento, Execução, Monitoramento e Controle e Encerramento) e trinta e sete processos distribuídos entre as áreas citadas anteriormente.

O guia de melhores práticas para o gerenciamento de projetos (PMBOK) define 0 projeto como um empreendimento único e temporário, ou seja, ele possui prazos muito bem definidos. O gerenciamento de projetos é diferente do gerenciamento das operações, pois elas têm o objetivo de executar tarefas rotineiras e repetitivas, logo são tarefas distintas. Os guias de melhores práticas para o gerenciamento de projetos buscam deixar claro e evidente que há grande diferença entre processos de projetos e processos de operações. Todos os projetos possuem fatores críticos para seu sucesso independente de seu porte, ou seja, há fatores críticos tanto para projetos de

Disponível em: https://www.nucleodoconhecimento.com.br/tecnologia/administracao-da- 
porte pequeno, quanto para empreendimentos gigantescos. Tais fatores devem ser levantados e analisados por profissionais experientes, esses utilizam processos, métodos, conhecimentos e ferramentas a fim de que não haja surpresas no decorrer da execução do empreendimento e consequentemente, não colocando o sucesso da conclusão em risco. O risco é outro ponto muito importante que deve também ser gerenciado, concomitantemente, com os fatos críticos, pois eles podem evoluir ou modificar ao longo do projeto. O gerenciamento de risco no PMBOK é composto por seis processos, são estes: 1) Planejar o gerenciamento dos riscos, 2) Identificar os riscos, 3) Realizar a análise qualitativa dos riscos, 4) Realizar a análise quantitativa dos riscos, 5) Planejar as respostas aos riscos e 6) Controlar os riscos. Como se pode constatar, deve-se dar muita importância ao gerenciamento dos riscos, pois se assim não o fizer, certamente, a conclusão do projeto estará em risco.

Além dele, Vargas (2002) cita que o projeto é exclusivo e composto por prazos muito bem definidos, cita também que se deve buscar o equilíbrio entre o escopo, o tempo e o custo - a fim de produzir projetos com qualidade e eficácia.

Em conformidade com as características citadas acima, infere-se que para um projeto tenha sucesso, deve-se utilizar ferramentas, métodos e conhecimentos específicos. O gerenciamento de projetos leva em consideração não só as políticas da organização, mas também o tipo da sua estrutura. Os tipos de estrutura organizacional variam entre funcional, matricial e projetizada, quanto mais próximo da estrutura projetizada a organização estiver, mais autonomia o gerente de projetos tem sobre seu gerenciamento e quanto mais próximo da estrutura organizacional funcional estiver, o gerente de projetos menos tem autonomia e aplicabilidade (VARGAS, 2002).

O gerenciamento de projetos sustentáveis e inovadores tornou-se um importante meio diferencial para as organizações contemporâneas. Atualmente, os clientes têm buscado, no mercado, opções que atendam suas demandas e concomitantemente leva-se em consideração a sustentabilidade no processo de produção. É evidente que o mundo está passando por transformações tanto econômica, quanto social, com isso, paulatinamente, as pessoas estão buscando adquirir produtos de empresas que 
levem a sério o meio sustentável, pois de maneira direta ou indireta impactará em sua vida. Observando esse cenário, várias empresas têm utilizado desse meio como um diferencial competitivo num mercado cada vez mais cruel e impessoal.

Conforme Bouer e Carvalho (2005), empresas têm buscado gerenciar seus respectivos projetos levando em consideração tanto a inovação, quanto a sustentabilidade a fim de que propiciem soluções com maior velocidade, qualidade e eficácia.

Hodiernamente, os projetos visam propiciar inovação, agilidade, eficiência e eficácia na criação e nas mudanças necessárias às adaptações das organizações a um ambiente instável, competitivo, seguro e de qualidade, levando-se em consideração a sustentabilidade. Hodiernamente, impõe-se às organizações desafios relacionados ao desenvolvimento de suas atividades de modo inovador e sustentável em um mercado competitivo e impessoal.

\section{SUSTENTABILIDADE NAS ORGANIZAÇÕES CONTEMPORÂNEAS}

Atualmente, ouve-se falar muito em sustentabilidade, mas afinal o que é ser sustentável? O termo vem do latim e originou-se na década de 80 , naquela ocasião houve uma conscientização entre os países e eles precisavam descobrir meios de propiciar o crescimento econômico levando em consideração o meio ambiente e o bem-estar da sociedade, sobretudo das próximas gerações. Segundo Savitz e Weber (2007), a sustentabilidade na verdade vai muito além do apenas o meio ambiente, leva-se em consideração um tripé composto pela economia, social e ambiental. Os produtos sustentáveis vieram para ficar, pois paulatinamente, a sociedade tem preferido marcas que levam em consideração não apenas o processo de produção, mas também seu descarte e estilo de mão de obra utilizada.

Segundo Miles; Munilla e Darroch (2009), os empresários têm se preocupado com a inovação dos produtos levando-se em consideração a sustentabilidade baseada na economia, meio ambiente, processos sociais e a utilização dos meios de maneira inteligente. Bem como, Gonçalves e Pirani (2007) afirmam que a introdução da

Disponível em: https://www.nucleodoconhecimento.com.br/tecnologia/administracao-da- 
sustentabilidade nos modelos de gestão organizacional tem sido um dos principais objetivos das organizações contemporaneamente, e de seus respectivos líderes, tais como: presidentes, diretores e de forma geral os funcionários. Esse desejo tem surgido, paulatinamente, a fim de atender as demandas do mercado consumidor contemporâneo, na qual as organizações devem ser socialmente responsáveis com o meio ambiente, propondo planos e ações que compreendam as dimensões ambiental e social.

Conforme Dalé; Roldan e Hansen (2011), a mídia colocou-se a favor das pressões ambientais e propondo medidas cabíveis a fim de atender as demandas de modo sustentável. Essas medidas não são apenas de responsabilidade das organizações, bem como de todos os integrantes que fazem parte do conjunto de etapas de desenvolvimento. Logo, pode-se inferir que todos precisam estar comprometidos no desenvolvimento de projetos visando uma produção inovadora sem esquecer da sustentabilidade.

Diante desse contexto de amplas exigências, algumas organizações já estão aderindo à sustentabilidade em seu processo de produção dos novos projetos e produtos a fim de reduzir diversos impactos negativos tanto ambiental, quanto social. Elas têm evidenciado tal comportamento de modo transparente para seus clientes por meio da publicidade e em seus rótulos.

O volume de informação que é gerado e armazenado diariamente na nuvem é absurdamente gigantesco. Com o advento da computação na nuvem, inúmeras pessoas passaram a armazenar suas informações em Data Centers. Eles são computadores de alta performance a fim de armazenar grande quantidade de dados. O consumo de energia elétrica em Data Centers é assombroso, então por que não pensar de modo sustentável quanto a essa questão? Foi isso que grandes empresas, como a Microsoft e Facebook têm se baseado. A Microsoft a fim de minimizar o impacto energético, no ano de 2018, submeteu um Data Center no mar da Escócia a fim de obter refrigeração dos equipamentos por meio das águas geladas desse país nórdico. No dia 14 de setembro de 2020, retirou-se tal Data Center para análises e 
constataram que foi um sucesso, pois o processamento ocorreu sem nenhuma alteração e a refrigeração ocorreu com êxito. A Microsoft com essa inovação tecnológica, administrar suas informações, gerou uma economia de milhares de dólares em seus cofres, além dessa tecnologia, ela também criará Data Center que consome energia eólica, luz solar e hidrelétricas. A empresa Facebook está criando um complexo na região Ártica, esse complexo abrangerá Data Centers que terão um grande volume de dados tanto para armazenar, quanto para processar. A fim de gerar economia com a refrigeração deste complexo, utilizou-se o clima como meio de refrigeração.

\section{CONSIDERAÇÕES FINAIS}

Pode-se inferir que a Tecnologia da Informação unida a inovação e sustentabilidade na administração da informação pode e certamente contribuirá com o desenvolvimento das organizações e gerará preservação dos recursos naturais, os quais estão, paulatinamente, escasseando. Portanto, projetos e processos sustentáveis podem gerar economia na produção e consequentemente, gerando-se mais lucros para a empresa. Além disso, a sustentabilidade na administração da informação utilizando-se ferramentas apropriadas podem gerar relatórios a fim de que executivos tenham em mãos dados precisos de seu mercado consumidor. É evidente que o planeta está passando por transformações ambientais e consequentemente, impactando toda a sociedade de maneira direta ou indireta, portanto não podemos ficar com os braços cruzados. Utilizando-se ferramentas inovadoras de tecnologia da informação que visa não apenas o lucro, mas também a questão sustentável, as empresas podem obter grandes vantagens competitivas, pois empresas que não utilizam administração da informação por meio do tema sustentável tendem a perder seu mercado para seus concorrentes. É necessária uma ação conjunta entre produtores e clientes, não apenas no processo de produção, consumo, mas também no processo de descarte. Constantemente, vimos por meio de revistas e jornais que o oceano tem sofrido com os resíduos descartados de modo inapropriado e diversos animais estão morrendo por isso. Algumas ações já estão sendo tomadas, porém há ainda muito para se fazer. Portanto, há uma enorme oportunidade no mercado para a

Disponível em: https://www.nucleodoconhecimento.com.br/tecnologia/administracao-da- 
criação e a melhoria de processos, ferramentas, técnicas e conhecimento levando em consideração a sustentabilidade e a inovação. Deve-se a importância de buscar ampla colaboração a fim de propiciar o compartilhamento de informações, conhecimentos, ferramentas e processos que foram utilizados e obtiveram êxito a fim de que todos ganhem com isso, sobretudo o meio ambiente. A colaboração viabiliza diálogos, e tais diálogos viabilizam colaboração, ou seja, um está intrinsecamente ligado ao outro. As organizações geralmente não inovam sozinhas, elas buscam avaliar o mercado e empresas concorrentes a fim de evoluir seus respectivos produtos e desenvolver novos produtos. Hoje, um diferencial no mercado são projetos que aderem não só a inovação, mas também a sustentabilidade, ou seja, gerar economia que atenda as demandas do mercado de modo equilibrado. É pertinente refletirmos sobre a comunicação, colaboração, sustentabilidade e inovação.

Conforme Vargas (2002), a comunicação e a colaboração são essenciais para produzir novos projetos e produtos que atendam às demandas do mercado. Gestores avaliam seus respectivos portfólios por meio da comunicação e decidem quais projetos devem ter prioridade de produção e quais devem ser descartados, ou seja, a comunicação e a colaboração é de grande valia nas tomadas de decisões. Tanto a colaboração, quanto a comunicação podem e certamente, irão auxiliar os gestores a fim de obterem ideias e oportunidades com inovação e sustentabilidade.

Infere-se, portanto, que o mercado produtivo tem sofrido mudanças ao longo dos anos devido a necessidade da adequação com o meio ambiente. Paulatinamente, a sociedade tem buscado adquirir produtos que foram levados em consideração a inovação e a sustentabilidade, país isso, a tecnologia da informação vem ao encontro, pois disponibiliza processos, ferramentas e conhecimento para a gerenciar a criação e manutenção de projetos. Ferramentas e processos para gerenciar grandes massas de dados, como Big Data tem sido utilizado unido a Mineração de Dados para propiciar produtos inovadores levando em consideração a sustentabilidade. 


\section{REFERÊNCIAS}

BOM, Jan van. ITIL: Guia de Referência. Rio de Janeiro: Campus, 2012.

BOUER, R.; CARVALHO, M. M. Metodologia singular de gestão de projetos: condição suficiente para a maturidade em gestão de projetos? Revista Produção. São Paulo, 2005.

DALÉ, L. B. C.; ROLDAN, L. B.; HANSEN, P. B. Analysis of Sustainability Incorporation by Industrial Supply Chain in Rio Grande do Sul State (Brazil) Journal of Operations and Project Management, 2011.

ISACA. COBIT 5. A Business Framework for the Governance and Management of Enterprise IT. Brazilian Portuguese Version.

PROJECT MANAGEMENT INSTITUTE. A guide to the project management body of knowledge. 3 ed. Newtown Square, 2004.

SAVITZ, A. W.; WEBER, K. A empresa sustentável: o verdadeiro sucesso é o lucro com responsabilidade social e ambiental. Rio de Janeiro: Elsevier, 2007.

VARGAS, R. V. Gerenciamento de projetos: estabelecendo diferenças competitivas. 3 ed. Rio de Janeiro, Brasport Hall, 2002.

Enviado: Dezembro, 2020.

Aprovado: Janeiro, 2021. 